\title{
Comparative Physico-Chemical Characterization of the Mucilages of Two Cactus Pears (Opuntia spp.) Obtained from Mekelle, Northern Ethiopia
}

\author{
Naod Gebresamuel $^{1,2 *}$, Tsige Gebre-Mariam ${ }^{1}$ \\ ${ }^{1}$ Department of Pharmaceutics, School of Pharmacy, Addis Ababa University, Addis Ababa, Ethiopia; ${ }^{2}$ Department of Pharmacy, \\ College of Health Sciences, Mekelle University, Mekelle, Ethiopia. \\ Email: ${ }^{*}$ reachnaod@yahoo.com
}

Received October $14^{\text {th }}, 2011$; revised November $17^{\text {th }}, 2011$; accepted December $8^{\text {th }}, 2011$

\begin{abstract}
Cactus is a plant that naturally grows in tropical and semi-tropical regions of the world. The composition of this mucilage is believed to differ from species to species. Hence, comparative study was carried out on mucilages of Opuntia ficus-indica (OFI) and Opuntia stricta (OS) as regard to their physico-chemical properties and acute toxicity levels. The study indicated that solubility of the dry mucilages were comparable and increased as raise in temperature. However, at all temperature levels the swelling powers were significantly higher in mucilage of OS than that of OFI. At $100 \%$ RH the moisture sorption property of OFI $(95.4 \%)$ was higher than that of OS $(76.9 \%)$. The pH values of both mucilages at $12 \%$ dispersions were found to be 5.57 and 5.87 for OFI and OS, respectively. The conductivity at the same concentration, $12 \%(\mathrm{w} / \mathrm{v})$, of OFI was $13.12 \mathrm{mS} / \mathrm{cm}$ while that of OS was $9.31 \mathrm{mS} / \mathrm{cm}$. The apparent viscosities at $12 \%(\mathrm{w} / \mathrm{v})$ were $9017 \mathrm{mPas}$ and 10,060 mPas for OFI and OS, respectively. The apparent viscosities of the dispersions decreased with increase in shear rates which rendered the dispersions a pseudoplastic flow. The surface tension of the aqueous dispersions of OFI $(28.71 \mathrm{mN} / \mathrm{M})$ decreased significantly as compared to that of OS $(39.7 \mathrm{mN} / \mathrm{M})$. The results of the study proved that the mucilage of OS was superior to OFI mucilage for use as food and pharmaceutical excipients. Moreover, both mucilages exhibited low acute toxicity levels.
\end{abstract}

Keywords: Density; Moisture Content; Mucilage; Opuntia Ficus Indica; Opuntia Stricta; Swelling Power

\section{Introduction}

Cactus (Opuntia spp.), Cactaceae family, is well adapted to arid and hot drylands, where the plants have a marked capacity to withstand prolonged drought. The ability of Cactaceae to retain water under an unfavorable climatic condition is due, in part, to the water-binding capacity of mucilage [1]. Mucilage is a complex carbohydrate [2] with a highly branched structure, which contains varying proportions of L-arabinose, D-galactose, L-rhamnose and D-xylose, as well as galacturonic acid in different proportions $[3,4]$. However, the mucilage composition was found to differ among different cactus species and among different areas within a species [5].

It was reported that cactaceae family has over 400 species [6] which some of them are traditionally used for many purposes. Since recent times there are literatures that suggest on the potential use of cactus mucilage as flocculating agent [7] and thickening agents [4].

Even though percentage yield and few physico-chemi-

"Corresponding author. cal properties has been determined elsewhere [1,4,8], most of them are done on the mucilage of Opuntia ficus indica species type while little is done on the rest of Opuntia spp. Moreover, the yield and quality of mucilage varies as to the above sources. This variation is attributed to species type, age of the cladode, the season of collection and also topography variation like rain distribution [2], temperature [8], soil type etc, for which Ethiopia can be different from the areas on which the previous works were done.

Hence, this work focuses on the characterization, comparison of the physico-chemical characteristics, acute toxicity and microbial load study on the mucilages extracted from the two abundantly growing cactus species (Figure 1) around Mekelle, Northern Ethiopia.

\section{Materials and Methods}

\subsection{Materials}

\subsubsection{Plant Materials}

Fresh cactus cladodes were randomly collected, in the 


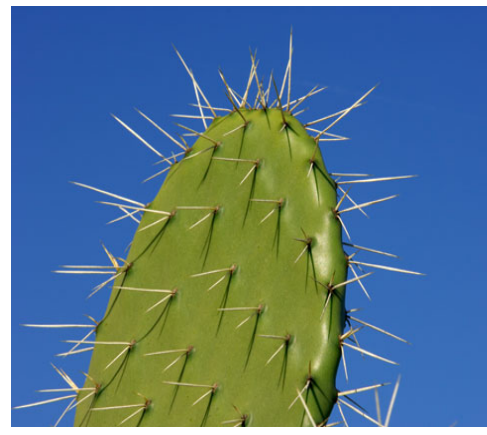

(a)

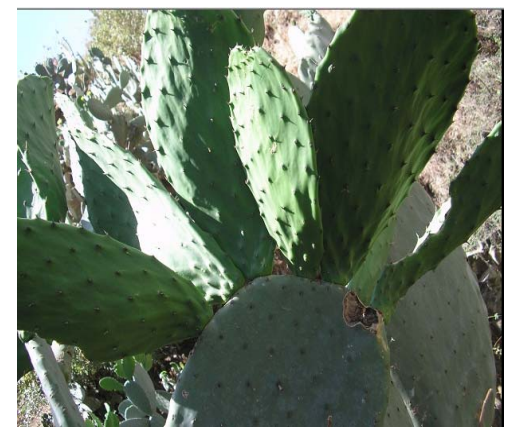

(b)

Figure 1. The two most common types of Opuntia spp. growing around Mekelle, Northern Ethiopia. (a) Opuntia ficus indica (locally known as “Ashak Beles”); (b) Opuntia stricta (locally known as "Lommo Beles”).

months of February and March 2009, from Mekelle area (2239 m, ASL), Northern Ethiopia. The plants were taxonomically identified at the Department of Biology, Addis Ababa University. Voucher specimens of Opuntia stricta (NGS001) (locally known as "Lommo beles") and Opuntia ficus-indica (NGS002) (locally known as "Ashak beles") are deposited at the Department of Biology, AAU Herbarium.

\subsubsection{Chemicals}

Tryptone Soya Agar Medium and Chloramphenicol Selective Supplement (Oxoid Ltd, England), Dichloran Rose Bengal Agar Medium (BDH, England), 1\% saline-peptone (BDH, England), Sodium Chloride, Sodium Hydroxide (LABMERK CHEMICALS, India) and Ethanol 96\% (DELF, Ethiopia) were used as received.

\subsection{Methods}

\subsubsection{Mucilage Extraction}

Extraction of the mucilage was done according to the method reported elsewhere [4].

\subsubsection{Physico-Chemical Characterization of the Mucilages}

\subsubsection{Powder Properties}

The densities (bulk and tapped densities), density related properties (Carr's index and Hausner ratio) and angle of repose/flow rate were determined based on the methods used elsewhere [9]. The true densities of the samples were determined with liquid displacement technique in $50 \mathrm{ml}$ Pycnometer with the help of toluene (density 0.865 $\mathrm{g} \cdot \mathrm{ml}^{-1}$ ) as the organic solvent. Results recorded are averages of three determinations.

\subsubsection{Solubility and Swelling Power}

These properties were determined based on the method described elsewhere [10], with slight modification. From each sample, $0.125 \mathrm{~g}$ was dispersed in $10 \mathrm{ml}$ of distilled water in a centrifuge test tube. The dispersion was heated, under mild agitation, in a thermostat at $40^{\circ} \mathrm{C}, 55^{\circ} \mathrm{C}, 65^{\circ} \mathrm{C}$, $75^{\circ} \mathrm{C}$ and $85^{\circ} \mathrm{C}$ for $10 \mathrm{~min}$. The tube was then removed from the water bath and immediately immersed in cold water for $5 \mathrm{~min}$ and centrifuged for $15 \mathrm{~min}$ at $3000 \mathrm{rpm}$. The supernatant was dried to constant weight in oven at $105^{\circ} \mathrm{C}$. The precipitated paste and the dried supernatant were then weighed. These properties were also evaluated at room temperature. The swelling power (SP) and solubility were calculated using Equations (1) and (2), respecttively. The results are averages of three determinations.

$$
\begin{aligned}
& \text { Swelling Power }[\mathrm{g} / \mathrm{g} \text { mucilage }]=\frac{m_{s w}}{\left(m_{o}-m_{s}\right)} \\
& \text { Solubility }[\mathrm{g} / 100 \mathrm{~g} \text { mucilage }]=\frac{m_{s}}{m_{o}} \times 100 \%
\end{aligned}
$$

where $m_{s w}$ is weight of swollen mucilage, $m_{o}$ is sample weight and $m_{s}$ is weight of dried supernatant.

\subsubsection{Moisture Sorption Properties of the Mucilages} The moisture sorption properties of the mucilages were done based on the method described elsewhere [11]. Pyrex dessicators containing saturated solutions or appropriate concentrations of $\mathrm{NaOH}$ solutions were prepared and stored at room temperature. $2 \mathrm{~g}$ of pre-dried mucilage was placed on dried and known weight petri dish and placed in metal frames and transferred to a particular relative humidity chamber. Samples were equilibrated for two weeks at room temperature. The moisture content, expressed as percent of weight of water by weight of solid, of each sample was determined based on the gravimetric method. Moisture sorption, at different RH (\%), recorded are average of two determinations.

\subsubsection{Chemical Compositions}

Ash values and crude fiber contents of the samples were determined based on the methods described elsewhere [12] and [13], respectively. 


\section{Determination of Fat Content}

The fat contents of the mucilages were determined by the soxhlet method. From each sample, 2 g of mucilage powder was placed in a thimble and plugged into a soxhlet extractor. $150 \mathrm{ml}$ of diethyl ether was poured into the thimble through an opening on the soxhlet apparatus. A predried and pre-weighed extraction flask was then assembled on the soxhlet as cover to the thimble and collect percolated diethyl ether. The assembled part was allowed to descend to a hot plate and kept for the first $1 \mathrm{hr}$ and then suspended for the next $3 \mathrm{hrs}$ for percolation. The fat contents of the mucilages were determined gravimetrically after oven-drying (at $92^{\circ} \mathrm{C}$ ) for $30 \mathrm{~min}$. Fat contents recorded are averages of three determinations.

\section{Determination of Protein Content}

Protein contents of the mucilages were analyzed using the Kjeldahl method; where the nitrogen content is multiplied by a factor of 6.25 to give protein content. From each sample, $0.5 \mathrm{~g}$ mucilage powder was digested at 400 ${ }^{\circ} \mathrm{C}$ in a digester using $6 \mathrm{ml}$ mixture of sulfuric acid and orthophospheric acid (100:5) in the presence of $0.5 \mathrm{ml}$ selenium and $100 \mathrm{ml}$ potassium sulphate. The solution was then distilled with sodium hydroxide (added in small quantity) which converts ammonium salt into ammonia. The ammonia was trapped using $1 \%(\mathrm{v} / \mathrm{v})$ boric acid and titrated using $0.1 \mathrm{~N} \mathrm{HCl}$ solution until end point was reached. Both distillation and titration and with subsequent determination of nitrogen and protein content were automatically done by the Microkjeldahl apparatus. Protein contents recorded are averages of three determinations.

\subsubsection{Surface Tension}

From each sample, $0.5 \mathrm{~g}$ of mucilage powder was first dispersed in distilled water to prepare $1 \%(\mathrm{w} / \mathrm{v})$ and then placed in a thermostat at $80^{\circ} \mathrm{C}$ for $1 \mathrm{hr}$ with continuous stirring. The sample was then removed and cooled to room temperature. The Wilhelmy plate method was used (with a plate length of $6.5 \mathrm{~cm}$ and thickness of $0.3 \mathrm{~cm}$ ). Surface tension data were taken $1 \mathrm{hr}$ after placing the plate on the dispersion surface, to ensure the steady-state had reached. Results are averages of three determinations.

\subsubsection{Conductivity and $\mathrm{pH}$}

First different masses of mucilage powder $(0.2 \mathrm{~g}, 0.8 \mathrm{~g}$, $1.6 \mathrm{~g}$ and $2.4 \mathrm{~g}$ ) from each sample were dispersed in distilled water, at room temperature, to prepare $1 \%, 4 \%, 8 \%$ and $12 \%(\mathrm{w} / \mathrm{v})$ dispersions, respectively. The dispersions were stirred using magnetic stirrer for 2 hrs. Conductivity was determined using conductometer and $\mathrm{pH}$ with $\mathrm{pH}$ meter. All tests were performed in triplicate.

\subsubsection{Viscosity}

Effect of mucilage concentration on apparent viscosity: Different masses of mucilage powder ( $2 \mathrm{~g}, 4 \mathrm{~g}$ and $6 \mathrm{~g})$, from each sample, were dispersed in portions of distilled water. The dispersion was adjusted to volume $(50 \mathrm{ml})$ using distilled water with continuous stirring. The preparations were then kept overnight at room temperature. Viscosity measurements of the dispersions were made using spindle number 4 of rotational viscometer at shear rate of $20 \mathrm{rpm}$. The results are averages of two determinations.

Effect of shear rate on apparent viscosity: $6 \mathrm{~g}$ of mucilage powder, from each sample, was dispersed in portion of distilled water. The dispersion was adjusted to volume $(50 \mathrm{ml})$ using distilled water with continuous stirring. The preparation was then kept overnight at room temperature. The measurements of the viscosities of the dispersion were made using spindle No. 4 of the rotational viscometer at various shear rates. Results of the property recorded are averages of two determinations.

\subsubsection{Preliminary Phytochemical Screening}

The mucilages were screened for secondary metabolites. Test for alkaloids, steroidal compounds and tannins were carried out based on the methods employed elsewhere [14] while flavonoids and saponins were determined on standard procedures [15].

\subsubsection{Microbial Loads}

The microbial loads of the mucilages were determined based on the pour plate method described in the USP/NF [16]. Total viable aerobic counts (TVAC) of the mucilages were done using 1\% Saline-Peptone as diluent and Tryptone Soya Agar as medium. Controls used were Tryptone Soya Agar Medium and combination of 1\% Saline-Peptone and Tryptone Soya Agar Medium. TVAC recorded are average of two determinations. Similarly, the Total Combined Molds and Yeasts Count (TCMYC) were performed as above, except for using Dichloran Rose Bangal Agar Medium, instead of Tryptone Soya Agar Medium. Controls used were Dichloran Rose Bangal Agar Medium and also combination of Dichloran Rose Bangal Agar Medium and 1\% Saline-Peptone.

\subsubsection{Acute Toxicity}

Acute toxicity study was carried out according to the method reported elsewhere [17]. Female mice, fasted for overnight, which age 6 weeks - 8 weeks were used. The mice were divided into three groups each comprising six mice. The control group received $33.3 \mathrm{ml} / \mathrm{kg}$ of distilled water while the second and third groups received 5000 $\mathrm{mg} / \mathrm{kg}$ of mucilage suspension of OFI and OS, respectively, in distilled water, orally. The animals were obse- 
rved for behavioral changes for the following $4 \mathrm{hrs}$. The animals were also observed for mortality for the following two weeks.

\subsubsection{Statistical Analysis}

ANOVA was carried out for the physico-chemical properties of the two mucilages and physical stability test of the suspensions from the three suspending agents using the computer software Sigmastat 3.5. Holm-Sidak multiple comparison test was used. At $95 \%$ confidence interval, $p$ values less than or equal to 0.05 were considered significant.

\section{Results and Discussion}

\subsection{Physico-Chemical Properties of the Mucilages}

\subsubsection{Powder Properties}

Unlike bulk and tapped densities, the true density of mucilage from OFI $\left(1.52 \mathrm{~g} \cdot \mathrm{ml}^{-1}\right)$ was significantly higher than that of OS $\left(1.36 \mathrm{~g} \cdot \mathrm{ml}^{-1}\right)$ (Table 1). Moreover, the values of Carr's index (\%) of OFI and OS indicate to exhibit fair and good flow properties, respectively. In addition, based on their Hausner ratio values both mucilages of OFI (1.23) and OS (1.18) have good flowability. However, the mucilages generally didn't flow through a funnel (the general method employed for flowability study). This had been expected due to the hygroscopic nature, high moisture content and fineness $(<224 \mu \mathrm{m})$ of the mucilage particles.

\subsubsection{Chemical Compositions}

The functional properties of additives can be affected by their chemical composition. The compositions of the mucilages from the two Opuntia spp. are presented in Table 2. The differences in the mucilage composition of the two species could be due to the variation in chemical composition of the soil and the complex phenomenon used by the plants to absorb their nutrients from it [4]. The fat content of OFI is higher than that of OS but not significantly different. The ash values and protein contents of OFI mucilage were comparable to those reported by elsewhere [4]. The moisture content of OS (11.72\%) was slightly higher than that OFI (11.57\%).

\subsubsection{Solubility and Swelling Power}

The mucilage of OFI was slightly more soluble than that of OS at all temperature levels studied (Table 3) which may be attributed to the difference in composition. In a study it was found OFI's mucilage to possess water soluble sugar molecules [18]. However, detailed studies on OS are lacking.

The swelling powers of the mucilages of OS were hig- her than those of OFI at all treatment levels. These might be due to the presence of relatively higher lipid/fats in OFI's mucilage than in OS. Fats are known to inhibit swelling probably by forming insoluble complexes [11, 19]. The difference in swelling power can also be associated with the abilities of the mucilages to absorb moisture-water holding capacity (WHC). Calcuim ion exists in the cactus mucilage as calcium-oxalate [20]. This biomineral of the mucilage has strong effect in molecular conformation which in turn leads to positive effect on water holding capacity of the cactus mucilage [21]. Hence, difference in calcium-oxalate content could be responsible for the difference in WHC which in turn brings difference in the swelling power of the mucilage and moisture content difference.

Table 1. Density and density related properties of the cactus mucilage powders (Mean $\pm S D, n=3$ ).

\begin{tabular}{lcc}
\hline Properties & OFI & OS \\
\hline Bulk density $(\mathrm{g} / \mathrm{ml})$ & $0.68 \pm 0.02^{\mathrm{a}}$ & $0.69 \pm 0.01^{\mathrm{a}}$ \\
Tapped density $(\mathrm{g} / \mathrm{ml})$ & $0.85 \pm 0.02^{\mathrm{a}}$ & $0.81 \pm 0.03^{\mathrm{a}}$ \\
True density $(\mathrm{g} / \mathrm{ml})$ & $1.52 \pm 0.04^{\mathrm{a}}$ & $1.36 \pm 0.07^{\mathrm{b}}$ \\
Carr's index $(\%)$ & $18.82 \pm 1.85$ & $15.20 \pm 2.52$ \\
Hausner ratio & $1.23 \pm 0.03$ & $1.18 \pm 0.04$ \\
\hline
\end{tabular}

The different letters $(\mathrm{a}, \mathrm{b})$ indicate the presence of significant difference $(\mathrm{p} \leq$ $0.5)$ between the species for a given property.

Table 2. Chemical compositions of the mucilages (Mean \pm $\mathrm{SD}, \mathbf{n}=3$ ).

\begin{tabular}{lcc}
\hline Chemical composition & OFI & OS \\
\hline Ash value (\%) & $33.96 \pm 0.06^{\mathrm{a}}$ & $29.93 \pm 0.05^{\mathrm{b}}$ \\
Crude fiber content (\%) & $0.06 \pm 0.01^{\mathrm{a}}$ & $0.07 \pm 0.03^{\mathrm{a}}$ \\
Fat content (\%) & $0.42 \pm 0.03^{\mathrm{a}}$ & $0.38 \pm 0.06^{\mathrm{a}}$ \\
Moisture content (\%) & $11.57 \pm 0.02^{\mathrm{a}}$ & $11.72 \pm 0.04^{\mathrm{b}}$ \\
Protein content (\%) & $6.82 \pm 0.01^{\mathrm{a}}$ & $5.18 \pm 0.03^{\mathrm{b}}$ \\
\hline
\end{tabular}

The letters $(a, b)$ indicate significant difference $(\mathrm{p} \leq 0.5)$ between the species for a given chemical composition.

Table 3. Solubility and swelling power of the mucilages at different temperatures (Mean \pm SD, $n=3$ ).

\begin{tabular}{ccccc}
\hline \multirow{2}{*}{$\begin{array}{c}\text { Tem. } \\
\left({ }^{\circ} \mathrm{C}\right)\end{array}$} & \multicolumn{2}{c}{ Solubility (\%) } & \multicolumn{2}{c}{$\begin{array}{c}\text { Swelling power } \\
\text { (per gram of sample) }\end{array}$} \\
\cline { 2 - 5 } & OFI & OS & OFI & OS \\
\hline 15 & $54.41 \pm 3.22^{\mathrm{c}}$ & $49.63 \pm 2.41^{\mathrm{c}}$ & $3.15 \pm 0.17^{\mathrm{b}}$ & $4.66 \pm 0.38^{\mathrm{b}}$ \\
40 & $57.63 \pm 1.59^{\mathrm{b}, \mathrm{c}}$ & $54.40 \pm 1.60^{\mathrm{b}, \mathrm{c}}$ & $3.99 \pm 0.26^{\mathrm{b}, \mathrm{d}}$ & $5.41 \pm 0.42^{\mathrm{b}, \mathrm{c}}$ \\
55 & $62.16 \pm 4.43^{\mathrm{b}, \mathrm{c}}$ & $57.63 \pm 6.41^{\mathrm{b}, \mathrm{c}}$ & $5.01 \pm 0.60^{\mathrm{b}, \mathrm{c}}$ & $7.06 \pm 0.99^{\mathrm{b}, \mathrm{c}}$ \\
65 & $65.42 \pm 6.40^{\mathrm{a}, \mathrm{b}}$ & $63.24 \pm 4.82^{\mathrm{a}, \mathrm{b}}$ & $6.78 \pm 1.59^{\mathrm{a}, \mathrm{c}}$ & $9.01 \pm 2.96^{\mathrm{a}, \mathrm{c}}$ \\
75 & $68.00 \pm 3.21^{\mathrm{a}, \mathrm{b}}$ & $64.80 \pm 3.99^{\mathrm{a}, \mathrm{b}}$ & $6.68 \pm 0.78^{\mathrm{a}, \mathrm{c}}$ & $8.10 \pm 1.03^{\mathrm{b}, \mathrm{c}}$ \\
85 & $75.19 \pm 0.79^{\mathrm{a}}$ & $71.22 \pm 2.39^{\mathrm{a}}$ & $6.02 \pm 0.55^{\mathrm{a}, \mathrm{c}, \mathrm{d}}$ & $7.86 \pm 0.63^{\mathrm{b}, \mathrm{c}}$ \\
\hline
\end{tabular}

The letters $(a, b, c, d)$ indicate significant difference $(p \leq 0.5)$ among the treatments within a property in each Opuntia spp. 


\subsubsection{Moisture Sorption Properties}

Moisture sorption profiles of the two mucilages are depicted in Figure 2. Percent moisture sorbed ranged between $7.7 \%$ and $8.55 \%$ at $20 \%$ RH and $95.4 \%$ and $76.9 \%$ at $100 \% \mathrm{RH}$ for mucilages of OFI and OS, respectively. At higher percent RH, OFI mucilage absorbed more moisture than that of OS. This is due to the hydrophilic nature of the mucilage molecules of OFI. According to a study [4] the mucilage of OFI has hygroscopic nature. Another study [5] also reported that, at $100 \% \mathrm{RH}$, mucilage of OFI sorbed $75 \%$ moisture, a value lower than that of OFI mucilage examined in this study at the same \% RH. These differences could be attributed to the mucilage compositional differences that the cactus plants from different areas are known to have.

\subsubsection{Surface Tension}

At $20^{\circ} \mathrm{C}$ the surface tension of water is $72 \mathrm{mN} / \mathrm{M}$ [22]. This surface tension can be decreased by water soluble polymers. Hence, the surface tension of the aqueous mucilage dispersions of OFI $(28.71 \mathrm{mN} / \mathrm{M} \pm 1.39 \mathrm{mN} / \mathrm{M})$ showed significant decrease compared to that of OS (39.7 $\mathrm{mN} / \mathrm{M} \pm 2.95 \mathrm{mN} / \mathrm{M})$. This property of the mucilages is very important especially in suspension preparations. The decrease in surface tension of dispersions, following addition of polymers, can lead to an increase in the time required for redispersion [23]. This is because addition of polymers is followed by lowering of the surface tension which ultimately decreases sedimentation volume (\%) [24].

\subsubsection{Conductivity and $\mathrm{pH}$}

The conductivities of mucilage dispersions of OFI were higher than those of OS at all the treatment levels (Table 4). These variations may be attributed to the the presence of large amount of the divalent calcium and appreciable amount of the monovalent potassium ions the OFI's mucilage is known to have; but little is found in the literature about the mucilage of OS. The presence of electrolytes in the mucilages can be of value in the flocculation of suspension formulations. The $\mathrm{pH}$ values of the dispersions of OS were invariably higher than those of OFI (Table 4). All the mucilage dispersions had almost neutral $\mathrm{pH}$ values. This property of the mucilages adds to their quality for their use as pharmaceutical excipient because of their less acid nature.

\subsubsection{Viscosity}

Effect of mucilage concentration on apparent viscosity: Viscosity is one of the desired quality parameters of excipients for application in both food and pharmaceutical formulations especially for liquid preparations. The viscosities of the dispersions of the two mucilages were found to increase upon increasing the mucilage concentration (Table 5). At all treatment levels, the mucilage of OS had higher viscosities than those of OFI. However, the magnitude in viscosity of both mucilage types is sufficient to impart industrially desired consistency to liquid formulations especially in suspension preparations. A study [25] suggested on the potential use of cactus mucilages as natural thickeners.

Effect of shear rate on apparent viscosity: The effect of shear rate on apparent viscosities of the dispersions from the two mucilage samples is depicted in Figure 3. As can be seen in the Figure, with increase in shear rate the viscosities of the dispersions decreased rendering them pseudoplastic flow.

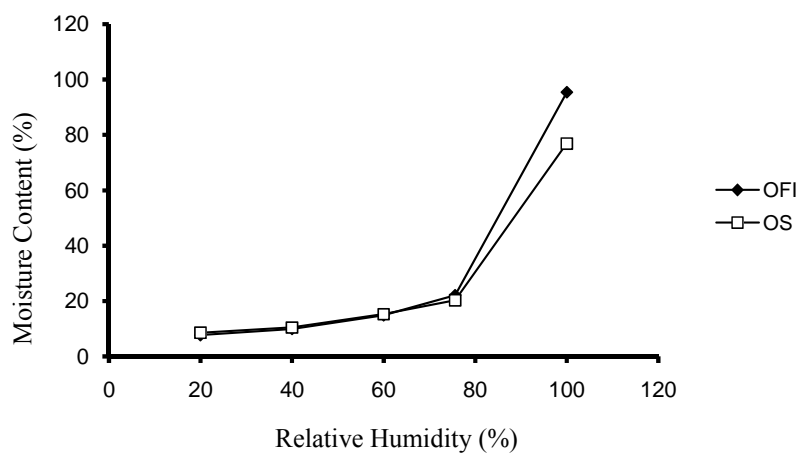

Figure 2. Moisture sorption profiles of the mucilages at different \% RH.

Table 4. Conductivity and pH of aqueous dispersion properties of the mucilages at different concentrations (Mean \pm $\mathrm{SD}, \mathrm{n}=3$ ).

\begin{tabular}{ccccc}
\hline \multirow{2}{*}{$\begin{array}{c}\text { Conc } \\
(\% \mathrm{w} / \mathrm{v})\end{array}$} & \multicolumn{2}{c}{ Conductivity $(\mathrm{mS} / \mathrm{cm})$} & \multicolumn{2}{c}{$\mathrm{pH}$} \\
\cline { 2 - 5 } & OFI & OS & OFI & OS \\
\hline 1 & $2.73 \pm 0.11^{\mathrm{a}}$ & $2.02 \pm 0.01^{\mathrm{a}}$ & $6.43 \pm 0.06^{\mathrm{a}}$ & $6.93 \pm 0.06^{\mathrm{a}}$ \\
4 & $9.69 \pm 0.64^{\mathrm{b}}$ & $5.43 \pm 0.61^{\mathrm{b}}$ & $6.03 \pm 0.21^{\mathrm{a}, \mathrm{b}}$ & $6.53 \pm 0.00^{\mathrm{b}}$ \\
8 & $12.04 \pm 0.55^{\mathrm{c}}$ & $8.09 \pm 0.62^{\mathrm{c}}$ & $5.80 \pm 0.09^{\mathrm{b}, \mathrm{c}}$ & $6.37 \pm 0.06^{\mathrm{c}}$ \\
12 & $13.12 \pm 0.05^{\mathrm{d}}$ & $9.31 \pm 0.08^{\mathrm{d}}$ & $5.57 \pm 0.06^{\mathrm{c}}$ & $5.87 \pm 0.12^{\mathrm{d}}$ \\
\hline
\end{tabular}

The letters $(a, b, c, d)$ indicate significant difference $(\mathrm{p} \leq 0.5)$ among the treatments in a given parameter for each Opuntia spp.

Table 5. Effect of mucilage concentration on apparent viscosity of their dispersions.

\begin{tabular}{ccc}
\hline \multirow{2}{*}{ Mucilage conc. in the dispersions (\% w/v) } & \multicolumn{2}{c}{ Apparent viscosity (mPas) } \\
\cline { 2 - 3 } & OFI & OS \\
\hline 4 & 1878 & 1728 \\
12 & 6119 & 6608 \\
& 9017 & 10,060 \\
\hline
\end{tabular}




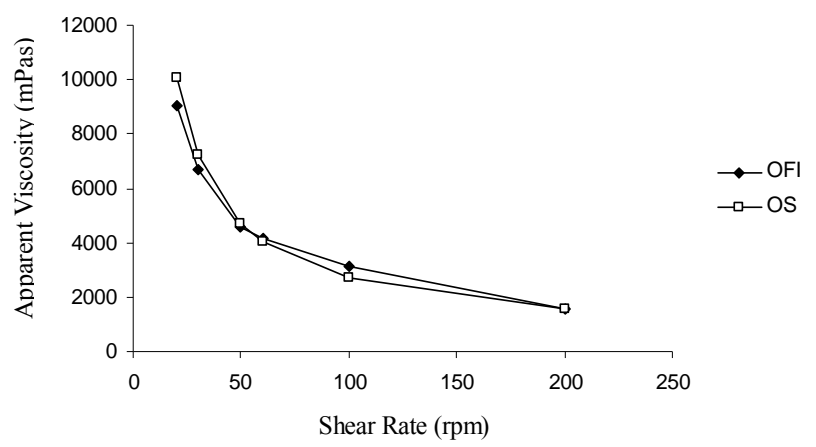

Figure 3. Apparent viscosities of mucilage dispersions (12\% $w / v)$ at different shear rates.

\subsection{Preliminary Phytochemical Screening}

Steroidal compounds, saponins and tannins were detected in the mucilage of the two Opuntia species. However, they were devoid of alkaloids and flavonoids (Table 6). As mucilage precipitation technique using ethanol tends to provide co-precipitation of other materials such as organic acids, certain salts, proteins, and other similar substances [26], the presence/absence of some secondary metabolites requires further analysis.

\subsection{Acute Toxicity}

The acute toxicity study revealed that the mucilages of the two Opuntia spp. have very low acute toxicity as the test mice did not show any behavioral changes for $4 \mathrm{hrs}$ following administration of mucilage dispersions of doses, $5 \mathrm{~g} / \mathrm{kg}$ body weight, equivalent to $300 \mathrm{~g}$ for a $60 \mathrm{~kg}$ adult human. In addition, no death was recorded in the following two weeks.

\subsection{Microbial Loads}

Results pertaining to both Total Combined Molds and Yeasts Count (TCMYC) and Total Viable Aerobic Count (TVAC) of the mucilages are presented in Table 7. OFI (217000 CFU per gram of sample) was found to have higher TVAC than that of OS (4000 CFU per gram of sample). Similarly, OFI (1600 CFU per gram of sample) had significantly higher TCMYC than OS (1100 CFU per gram of sample). However, the controls used for both TVAC and TCMYC were devoid of microorganisms.

For pharmaceutical excipients, the USP/NF (2009) recommends a maximum tolerable limit of 1000 and 100 CFU per gram of sample for TVAC and TCMYC, respectively. In this study, however, the extracts showed much higher values for both TVAC and TCMYC. As reported [18] glucose and galacturonic acid are the main sugars of Opuntia cladode, and the results obtained in this study could be partially attributed to the presence of these sugars. The high moisture content and the $\mathrm{pH}$ value together with the presumed presence of high content of soluble solids in the mucilages could make the mucilages suitable media for microbial growth [27]. In line with this a study showed that the amounts of bacterial colonies present in media enriched with mucilage of OFI were higher compared with the regular media (without mucilage) [28]. This suggests that the microbial load should be significantly reduced before the mucilages are used as pharmaceutical excipients.

\section{Conclusion}

Mucilages of the two cactus species, OFI and OS, were extracted and characterized. Both OFI and OS showed low toxicity levels. Characterization of the isolated mucilage powders revealed comparable results in properties such as bulk density, tapped density, solubility, crude fiber, fat, sorbed moisture content (at lower \% RH) and secondary metabolites. Mucilage of OFI showed higher values in properties like true density, ash value, moisture content, conductivity, sorbed moisture content (at higher $\% \mathrm{RH}$ ) and microbial load as compared to OS. However, the mucilage of OS was found to have higher values than that OFI in swelling power, surface tension, $\mathrm{pH}$ and viscosity. Generally, the mucilage from OS had superior quality to mucilage of OFI for use as pharmaceutical and food excipients/additives.

Table 6. Preliminary phytochemical screening of the mucilages.

\begin{tabular}{cccc}
\hline Tested for & Specific test/Reagent used & OFI & OS \\
\hline Alkaloids & Dragendorff's reagent & $(-)$ & $(-)$ \\
& Mayer's reagent & $(-)$ & $(-)$ \\
& Wagner's reagent & $(-)$ & $(-)$ \\
Flavonoids & Lead acetate & $(-)$ & $(-)$ \\
& Ethyl acetate & $(-)$ & $(-)$ \\
& Reaction with NaOH & $(-)$ & $(-)$ \\
Saponins & Froth test & $(+)$ & $(+)$ \\
Steroids & Salkowski's test & $(+)$ & $(+)$ \\
Tannins & Ferric chloride & $(+)$ & $(+)$ \\
\hline
\end{tabular}

Table 7. Microbial load of the mucilages at different dilutions.

\begin{tabular}{cccc}
\hline \multirow{2}{*}{ Parameter } & Dilutions & \multicolumn{2}{c}{ Average Microbial Load per Petri dish } \\
\cline { 3 - 4 } & $1: 100$ & Uncountable & OS \\
\hline TVAC $^{*}$ & $1: 1000$ & 217 & 4 \\
TCMYC $^{* *}$ & $1: 100$ & 16 & 11 \\
\hline
\end{tabular}

${ }^{*}$ Total viable aerobic counts; ${ }^{* *}$ TCMYC: Total Combined Molds and Yeasts Count. 


\section{Acknowledgements}

The authors are grateful to the School of Graduate Studies, Addis Ababa University for sponsoring this study, DACA and EHNRI for providing access to their laboratory facilities and finally EPHARM for providing raw materials.

\section{REFERENCES}

[1] A. Cárdenas, I. Higuera-Ciapara and F. Goycoolea, "Rheology and Aggregation of Cactus (Opuntia ficus-indica) Mucilage in Solution," Journal of the Professional Association Cactus Development, Vol. 2, 1997, 152-159.

[2] C. Sáenz, E. Sepúlveda and B. Matsuhiro, “Opuntia spp. Mucilage's: A Functional Component with Industrial Perspectives," Journal of Arid Environments, Vol. 57, No. 3, 2004, pp. 275-290. doi:10.1016/S0140-1963(03)00106-X

[3] B.S. Paulsen and P.S. Lund, "Water-Soluble Polysaccharides of Opuntia ficus-indica cv 'Burbank's Spineless'," Phytochemistry, Vol. 18, No. 4, 1979, pp. 569-571.

[4] E. Sepúlveda, C. Sáenz, E. Aliage and C. Aceituno, "Extraction and Characterization of Mucilage in Opuntia spp.," Journal of Arid Environments, Vol. 68, No. 4, 2007, pp. 534-545. doi:10.1016/j.jaridenv.2006.08.001

[5] S. Trachtenberg and A. M. Mayer, "Composition and Properties of Opuntia ficus-indica Mucilage," Phytochemistry, Vol. 20, No. 12, 1981, pp. 2665-2668. doi:10.1016/0031-9422(81)85263-6

[6] F. C. Stintizing, A. Schieber and R. Carle, "Phytochemical and Nutritional Significance of Cactus Pear," European Food Research and Technology, Vol. 212, No. 4, 2001, pp. 396-407. doi:10.1007/s002170000219

[7] K. A. Young, A. Anzalone, T. Pichler, M. Picquart and N. A. Alcantar, "The Mexican Cactus as a New Environmentally Benign Material for the Removal of Contaminants in Drinking Water," Material Research Society: Symposium JJ, Vol. 930, 2006.

[8] G. Goldstein, L. Andrade and P. Nobel, "Differences in Water Relations Parameters from the Chlorenchyma and the Parenchyma of the Opuntia ficus-indica under Wet versus Dry Conditions," Australian Journal of Plant Physiology, Vol. 18, No. 2, 1991, pp. 95-107. doi:10.1071/PP9910095

[9] A. Belete and T. Gebre-Mariam, "Formulation and Evaluation of Paracetamol Sustained Release Peroral Matrix Tablets Using Hydroxypropylmethylcellulose," Master's Thesis, School of Graduate Studies, Addis Ababa University, Addis Ababa, 2003.

[10] F. F. Takizawa, G. O. Silva, F. E. Konkel and I. M. Demiate, "Characterization of Tropical Starches Modified with Potassium Permanganate and Lactic Acid," Brazilian Archives of Biology and Technology, Vol. 47, No. 6, 2004, pp. 921-931.

[11] T. Gebre-Mariam and P. C. Schmidt, "Isolation and Physico-Chemical Properties of Enset Starch," Starch/Stärke, Vol. 48, No. 46, 1996, pp. 208-214. doi: $10.1002 /$ star. 19960480603
[12] E. A. Hassan, S. Al-Assaf, G. O. Phillips and G. A. Williams, "Studies on Acacia Gums: Part III Molecular Weight Characteristics of Acacia seyal var. seyal and Acacia seyal var. fistula," Food Hydrocolloids, Vol. 19, No. 4, 2005, pp. 699-677.

[13] M. Śmiechowska and P. Dmowski, "Crude Fiber as a Parameter in the Quality Evaluation of Tea," Food Chemistry, Vol. 94, No. 3, 2006, pp. 366-368. doi:10.1016/j.foodchem.2004.11.026

[14] A. M. Musa, A. B. Aliyu, A. H. Yaro, M. G. Magaji, H. S. Hassen and M. I. Abdullahi, "Preliminary Phytochemical, Analgesic and Anti-Inflammatory Studies of the Methanol Extract of Anisopus mannii (N.E.Br) (Asclepiadaceae) in Rodents," African Journal of Pharmacy and Pharmacology, Vol. 3, No. 8, 2009, pp. 374-378.

[15] A. Muzemil, A. Hymete, T. Mekuria and A. Abebe, "Determination of Artemisinin and Essential Oil Contents of Artemisia annua L. Grown in Ethiopia and in Vivo Antimalarial Activity of Its Crude Extracts against Plasmodium berghei in Mice," Master's Thesis, School of Graduate Studies, Addis Ababa University, Addis Ababa, 2008.

[16] USP/NF, "United States Pharmacopoeial Convention," Vol. 2, Rockville, 2009.

[17] R. Kumar, M. B. Patil, S. R. Patil and M. S. Paschapur, "Evaluation of Abelmoschus esculentus Mucilage as Suspending Agent in Paracetamol Suspension," International Journal PharmTech Research, Vol. 1, No. 3, 2009, pp. 658-665.

[18] G. Ginestra, M. L. Parker, R. N. Bennett, J. Robertson, G. Mandalari, A. Narbad, R. B. Lo Curto, G. Bisignano, C. B. Faulds and K. W. Waldron, "Anatomical, Chemical, and Biochemical Characterization of Cladodes from Prickly Pear (Opuntia ficus-indica (L.) Mill.)," Journal of Agricultural and Food Chemistry, Vol. 57, No. 21, 2009, pp. 10323-10330. doi:10.1021/jf9022096

[19] O. A. Odeku and K. M. Picker-Freyer, "Analysis of the Material and Tablet Formulation Properties of Four Dioscorea Starches," Starch/Stärke, Vol. 59, No. 9, 2007, pp. 430-444. doi:10.1002/star.200700619

[20] L. A. J. Garvie, "Decay of Cacti and Carbon Cycling," Naturwissenschaften, Vol. 93, No. 3, 2006, pp. 114-118. doi:10.1007/s00114-005-0069-7

[21] S. Trachtenberg and A. M. Mayer, "Calcium Oxalate Crystals in Opuntia ficus-indica (L.) Mill.: Development and Relation to Mucilage Cells-A Stereological Analysis," Protoplasma, Vol. 109, No. 3-4, 1981, pp. 271-283. doi:10.1007/BF01287447

[22] A. Faithi-Azarbayjani, A. Jouyban and S. Y. Chan, "Impact of Surface Tension in Pharmaceutical Sciences," Journal of Pharmacy and Pharmaceutical Sciences, Vol. 12, 2009, pp. 218-228.

[23] S. Yasueda, K. Inada, K. Matsuhisa, H. Terayam and A. Ohtori, "Evaluation of Ophthalmic Suspensions Using Surface Tension," European Journal of Pharmaceutics and Biopharmaceutics, Vol. 57, No. 2, 2004, pp. 377-382. doi:10.1016/S0939-6411(03)00159-0

[24] J. L. Zatz, L. Schnitzer and P. Sarpotdar, "Flocculation of Sulfamerazine Suspensions by a Cationic Polymer" Jour- 
nal of Pharmaceutical Sciences, Vol. 68, No. 12, 1979, pp. 1491-1494. doi:10.1002/jps.2600681207

[25] C. Sáenz, "Opuntia spp. Bioactive Compounds in Foods: A Plus for Health," Acta Horticulturae, Vol. 728, 2006, pp. 231-240.

[26] V. Natale, "Method of Isolating Mucilaginous Polysaccharides and Uses Thereof," US Patent No. 6482942, 2002.

[27] C. Sáenz, "Processing Technologies: An Alternative for
Cuctus Pear (Opuntia spp.) Fruits and Cladodes," Journal of Arid Environments, Vol. 46, No. 3, 2000, pp. 209-225. doi:10.1006/jare.2000.0676

[28] E. M. Yahia, J. D. E. J. Ornelas and A. Anaya, "Extraction and Chemical Characteristics of Mucilage from Mesquite, Aloe vera, Maguey and Prickly Pear Cactus Cladodes (Nopal) and Evaluation of Its Prebiotic Effect on the Growth of 2 Probiotic Bacteria," Acta Horticulturae, Vol. 841,2009 , pp. 625-628. 